\title{
Improving communication to tackle obesity in the UK
}

\author{
Susan A. Jebb*, Rebecca Lang and Adrian Penrose \\ MRC Human Nutrition Research, Elsie Widdowson Laboratory, Fulbourn Road, Cambridge CB1 9NL, UK
}

\begin{abstract}
Obesity is a serious health issue. In the UK the prevalence of obesity has trebled in the last 20 years and today one in five adults is clinically obese. Research shows that obesity is a predictable response to an environment that favours the consumption of energy-dense foods and allows minimal physical activity. This finding implies that the efficacy of public health messages to individuals to inform their lifestyle choices will be enhanced by environmental changes that support and facilitate healthy options. The present paper focuses on the importance of communicating scientific knowledge to the stakeholders with a responsibility for tackling obesity and addresses some of the barriers that are encountered.
\end{abstract}

\section{Obesity: Communication: Public health}

Obesity in the UK has trebled in the last 20 years and today $20 \%$ of the adult population are obese and a further $38 \%$ are overweight (Erens et al. 2001). In the USA the situation is much worse; $27 \%$ of the adult population and $10 \%$ of the children are obese (Williams et al. 2001). However, the rate of increase in the USA and UK is similar, suggesting that the prevalence of obesity in the UK is set to escalate unless effective action is taken to prevent further cases of obesity developing and to treat those with established obesity. Indeed, the prevalence of obesity in the UK today reflects that seen in the USA only 10 years ago (Fig. 1).

The incidence of premature death among obese individuals has increased two- to threefold (Calle et al. 1999), and there has been a sharp rise in morbidity, especially for type 2 diabetes (Chan et al. 1994; Colditz et al. 1995). Together with an increased risk of hypertension and dyslipidaemia, many of the excess deaths among obese individuals are attributable to cardiovascular disease. However, there are also strong links to some types of cancer, especially breast, colon and kidney cancer. Obese individuals are at increased risk from physical ailments, including respiratory disorders, joint problems and back pain. They suffer from higher rates of depression and anxiety, although it is unclear whether this outcome is a direct causal effect or a reflection of the psycho-social discrimination suffered by obese individuals, especially those with morbid obesity. The National Audit Office (2001) estimated that the net cost of obesity to the UK, including direct costs to the National Health Service and indirect costs to the wider economy, was $£ 2 \times 10^{9}$ per year.

Obesity is increasingly common, but it is not inevitable. Research into obesity has considered the impact of genes, metabolism, diet, physical activity and cognitive processes. It is now generally accepted that obesity develops in response to adverse environmental factors, which favour increased food consumption and decreased energy expenditure, set against a background of individual genetic susceptibility (Jebb, 1997). More detailed research has identified a clear framework for lifestyle changes that favour enhanced weight control, including reductions in the energy density of the diet, and increases in physical activity (Gill, 1997). However, these strategies, which are highly effective in carefullycontrolled experimental situations, appear almost futile in the public health context, in which environmental factors seem to overwhelm the physiological or cognitive abilities of many individuals to control their weight.

It is clear that while research into the causes of obesity is necessary to develop rational public health strategies, it is not sufficient to prevent or treat obesity. Scientists have a responsibility to provide the evidence base on which to build policy and practice, but a range of other stakeholders, including government (both central and local), manufacturers and retailers, employers, schools, health professionals and parents, must each recognise their role and responsibilities. Effective communication between all parties is essential to build a national framework that facilitates the necessary changes in lifestyle (Fig. 2). 


\section{Communicating the message}

Unlike many other areas of science, obesity does not need to battle to make the headlines, since news items or features on obesity appear on an almost daily basis. There is no shortage of information available to the public, but scientists must strive to be heard against the background orchestra of myths, miracle cures and vested interests. Consumers need enhanced quality not quantity of information. To this end, organisations such as the Association for the Study of Obesity have established formal channels through which obesity scientists can communicate with the media, and hence a wider audience. The Obesity Resource and Information Centre is a media information service that offers a range of background fact sheets on obesity and can

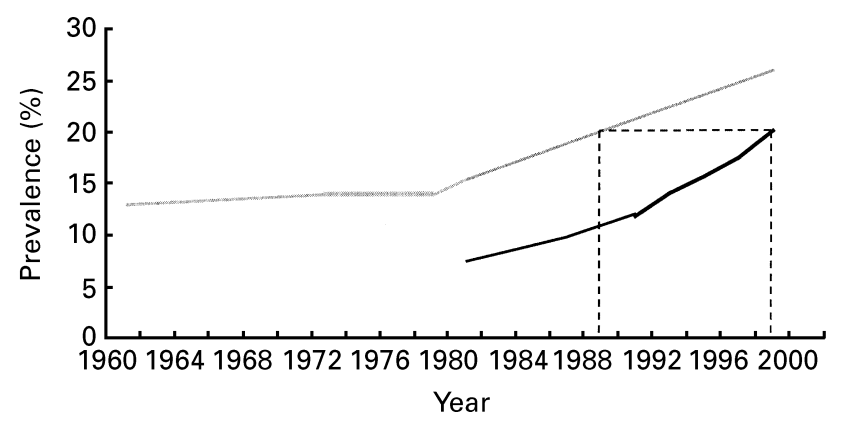

Fig. 1. Secular trends in obesity in the UK (-) and USA (-). (---), UK is where USA was 10 years ago. facilitate direct contact between journalists and members of the Association for the Study of Obesity who have expertise in all aspects of obesity research and management (www.aso.org.uk/oric). The provision of independent and authoritative information on obesity in a timely manner is an important step in promoting accurate and responsible reporting of obesity and other health issues. In this way scientists can help to put new findings in context, reducing the risk of new and unconfirmed reports reaching the front page, only to be apparently refuted the following week.

However, obesity cannot be tackled wholly through the media, and there is also a need for scientists to develop mechanisms to communicate with other stakeholders. In the UK the Medical Research Council has a commitment to the dissemination of scientific knowledge to improve public health. Through the activities of the nutrition communications group at MRC Human Nutrition Research, Cambridge, it is extending its liaison with other parts of government, charities, industry and the media to respond to their individual needs with respect to obesity and other areas in which nutrition makes an important contribution to public health (www.mrc-hnr.cam.ac.uk). It is increasingly taking a more proactive role to shape the obesity debate and foster effective policy and practice.

\section{Understanding the stages of change}

Communicating with the public through newspapers and magazines is a blunt instrument. Research in the behavioural sciences has developed useful models to describe the 'stage



Fig. 2. Stakeholders in weight management in England, UK. (Adapted from National Audit Office, 2001.) 
of change' of an individual at any moment in time, ranging through pre-contemplation, contemplation, preparation, action, maintenance and relapse (Prochaska \& Diclemente, 1986). These models acknowledge that the messages for individuals need to be tailored to their needs at the time. Thus, a pre-contemplation individual needs the motivation to even consider the need to make lifestyle changes, while an individual who has arrived at the action stage needs practical implementation strategies. Newspapers, and to a lesser extent magazines, sell to a broad cross-section of society with respect to their personal weight agenda. There is a temptation for scientists and journalists to leap to providing actionorientated messages, yet the majority of the population has not yet reached this stage of change, and hence the information fails to initiate change. Instead, more precisely targeted information is needed, e.g. a greater emphasis on messages which raise awareness of obesity in order to move individuals into the preparation stage. For others it may be useful to dispel some of the myths of obesity, which inhibit personal action by fostering a perception that body weight is a result of inevitable biological forces, such as genetic factors, which are not subject to voluntary control (Prentice et al. 1991).

\section{Goals and expectations}

In spite of the clear risks of obesity, health itself is rarely a motivating factor in an individuals' decision to lose weight. The social importance attached to slimness has never been greater, and the media play a part in both setting this agenda and also reflecting the wider culture obsession. This situation has many adverse ramifications, including a poor public perception of a healthy body size, pursuit of excessive thinness and unrealistic weight goals. The concept of an 'ideal body weight' has been an anathema to scientists for many years, yet still dominates the public agenda. There is an urgent need to communicate the concept of a range of healthy body weight and to focus on body composition, especially fatness per se, rather than absolute weight (Prentice \& Jebb, 2001). The BMI (weight/height ${ }^{2}$ ) is the reference method for assessing obesity. However, there are a number of limitations in its use as a communication tool; in individuals the BMI is a poor marker of adiposity and will mistakenly identify a well-developed musculature as obesity, and at a practical level it uses metric measurements and relies on the calculation of a relatively complex ratio. Instead, scientists have shown that the simpler measurement

Table 1. Waist circumferences and health risks associated with obesity in Caucasians (Han et al. 1995)

\begin{tabular}{lccc} 
& & \multicolumn{2}{c}{ Waist circumference } \\
\cline { 3 - 4 } & & Increased risk & Substantially-increased risk \\
\hline Men: & $\mathrm{m}$ & $\geq 0.94$ & $\geq 1.02$ \\
& in $^{*}$ & 37 & 40 \\
Women: $\mathrm{m}$ & $\geq 0.80$ & $\geq 0.88$ \\
& in $^{*}$ & 32 & 35 \\
\hline
\end{tabular}

*Approximate values. of waist circumference can provide a good indicator of obesity-related health risk (Table 1; Han et al. 1995). Given the success in familiarising the 'at-risk' population with their blood cholesterol level, communicating the measurement of waist circumference as a practical step to raise awareness of obesity should be achievable. Health professionals have an important communication role here too and should be encouraged to monitor weight, waist or fatness in their patients and to highlight any important trends.

Weight stability is the first goal in any campaign to tackle obesity. However, once obesity is identified there is a need to consider strategies for weight reduction. In the presentday society dominated by instant results, the recognition that even total starvation will only yield losses of $2-3 \mathrm{~kg}$ fat per week, and that a more realistic rate of weight loss is about $1 \mathrm{~kg}$ per week, is enough to deter many individuals from even embarking on a weight-loss programme. The conviction that 'there must be an easier way' is reinforced by a succession of advertisements and media features that claim larger weight losses achieved with minimum effort. Scientists acknowledge that there is no miracle cure for obesity that will allow individuals to eat, drink and watch TV with impunity. Instead, novel strategies to tackle body weight, including new pharmacological agents, aim to reinforce and supplement the impact of voluntary changes in lifestyle. Claims to the contrary provide false hope, discourage personal responsibility and undermine credible weight-management programmes.

In addition to wanting results fast, most obese individuals turn to social icons and role models to define an unrealistic weight target. Studies have shown that most patients entering a weight-loss programme wish to lose $>20 \%$ of their initial body weight (Jeffrey et al. 1998), yet sustained reductions of this magnitude are almost unachievable. Instead, there is clear evidence that improvements of 5-10\% body weight can bring substantial health benefits (Scottish Intercollegiate Guidelines Network, 1996). However, communicating this message is hampered by dramatic 'before and after' photos, which foster the illusion that large and rapid weight losses are a realistic goal. These images convey a much more striking message than bland facts and figures about triacylglycerols, insulin or blood pressure. It is necessary to harness the creative talents of the media in order to communicate the invisible health benefits of modest weight loss. However, it must be acknowledged that the poor public understanding of the hazards of obesity is fuelled not only by the media attention on cosmetic issues, but by the historical failure of doctors to acknowledge obesity as a health issue, worthy of their attention.

\section{Establishing clear messages}

Knowledge is not sufficient for weight control but it is a necessary part of the whole strategy. Communicating accurate information about weight management is difficult because there are no simple messages. Body weight is the integrated product of a lifetime's diet and activity habits. Most individuals gain excess weight gradually over many years as a consequence of imperceptible imbalances between energy intake and expenditure. It is rarely possible 
to identify a single aetiological factor for individuals or populations, and this situation provides ample opportunity for discord in proposed solutions. Public health is not served by any constituency focusing on diet or activity alone. It is necessary to recognise the environmental background of inactivity and relative over-consumption in which excess weight gain is an almost inevitable consequence of modern lifestyles (Egger \& Swinburn, 1997), while weight control demands the development and implementation of individual coping strategies to defend body weight. Positive action is required on all fronts, leaving individuals to utilise those initiatives most relevant to their own needs.

The recognition of the secular decline in physical activity is one of the great successes of scientific communication (Prentice \& Jebb, 1995). There is a general awareness of the difference in 21 st century lives relative to that of our grandparents, and the phrase 'sedentary lifestyles' has become part of mainstream vocabulary. However, there are legitimate scientific debates about the importance of energy turnover or aerobic fitness, which translate into public health confusion over the value of daily activities $v$. programmed exercise (McAuley et al. 2002). At a public health level any progress towards a more active lifestyle is likely to yield some benefit. Government policy must provide a framework that fosters and supports such initiatives, local communities need to take specific action to facilitate the adoption of active lifestyles, perhaps by providing opportunities for walking and cycling safely and the provision of affordable sports facilities, while employers and schools must look to develop opportunities for physical activity that contribute to a cultural shift in attitudes towards lifestyle-based activity (National Audit Office, 2001). In this way an active lifestyle will become the 'default' situation, implicitly encouraging individuals towards healthier lifestyle choices.

For diet the situation is even more complex. Sustained reductions in body weight will usually require a cut in energy intake, but responsible dietary management of obesity must also reduce the associated health risks (Jebb, 2002). Hence, diet composition becomes of paramount importance, and the message is therefore not just about energy content, but also about the proportion of macronutrients, the specific types of fat and carbohydrate and the additional health effects of fruits and vegetables. Unlike smoking-cessation programmes in which the single message 'Stop Smoking' is valid, stop eating is not an option to tackle obesity. Instead, there is a diverse collection of messages about the overall composition and nutritional balance of the diet, which can be difficult for consumers to assimilate, leading to a perception of scientific discord.

In recent years the message from nutrition scientists has focused on the need to reduce dietary fat, especially saturated fat. Here there is synergy between the dietary recommendations to reduce the risk of obesity and other chronic diseases, especially cardiovascular disease. Reductions in dietary fat are associated with marked improvements in dyslipidaemia and modest reductions in body weight. Since fat $(39 \mathrm{~kJ} / \mathrm{g})$ contains more than twice as much energy, weight-for-weight, as protein or carbohydrate $(<17 \mathrm{~kJ} / \mathrm{g})$, reductions in the proportion of fat leads to decreases in the energy density of the diet. This approach favours improved appetite control by reducing the risk of passive (accidental) over-consumption of energy in energy-dense foods (Prentice $\&$ Poppitt, 1996). However, low-fat high-carbohydrate diets are not a panacea for obesity, and the scientific debate regarding their health impact is providing effective ammunition to those who complain that scientists can never agree. Instead, there is a need to focus on energy density and to identify those dietary habits associated with an increased risk of over-consumption.

Managing the flow of scientific information to the public has become especially challenging in recent years. In a culture that demands openness and transparency the concept that scientific debate can be held behind closed doors is outdated. Advances in information technology allow the dissemination of scientific developments to the public more quickly than ever before, and the breakdown in trust between the public and those in authority has led to a greater consumer involvement in decision making, especially in the context of issues such as nutrition that have a direct impact on public health. This new relationship demands a sophisticated communication network. The status of emerging evidence must be clearly identified by putting it in context with existing knowledge and future research needs, and the public must also be aware of the source of the information in order to make an informed judgement about its credibility. This aspect is a particular challenge in a field as broad as nutrition, which lacks a clearly defined professional status. Initiatives such as the register of Accredited Nutritionists developed by the Nutrition Society are an important step forward. A responsible media can facilitate an informed dialogue between authoritative scientists and the public. However, it can also undermine the interests of both parties, not least by fostering controversy where little or none exists.

\section{Summary}

Obesity is arguably the greatest challenge to public health in Britain today, and there is a pressing need for immediate and effective action. The present paper has addressed some of the specific barriers to success, focusing on those areas in which improved communication between scientists and other stakeholders can make a positive contribution. It is only through concerted action, with all sectors of society working in partnership rather than isolation, that obesity can be tackled effectively.

\section{References}

Calle EE, Thun MJ, Petrelli JM, Rodriguez C \& Heath CW (1999) Body mass index and mortality in a prospective cohort of US adults. New England Journal of Medicine 341, 1097-1105.

Chan JM, Rimm EB, Colditz GA, Stampfer MJ \& Willett WC (1994) Obesity, fat distribution and weight gain as risk factors for clinical diabetes in men. Diabetes Care 17, 961-969.

Colditz GA, Willett WC, Rotnitzky A \& Manson JE (1995) Weight gain as a risk factor for clinical diabetes mellitus in women. Annals of Internal Medicine 122, 481-486.

Egger G \& Swinburn B (1997) An ecological approach to the obesity pandemic. British Medical Journal 315, 477-480.

Erens B, Primatesta P \& Prior G (2001) Health Survey for England. The Health of Minority Ethnic Groups 1999. London: Department of Health. 
Gill TP (1997) Key issues in the prevention of obesity. British Medical Bulletin 53, 359-388.

Han TS, van Leer EM, Seidell JC \& Lean ME (1995) Waist circumference action levels in the identification of cardiovascular risk factors: prevalence study in a random sample. British Medical Journal 311, 1401-1405.

Jebb SA (1997) Aetiology of obesity. British Medical Bulletin 53, 264-285.

Jebb SA (2002) Dietary strategies to prevent and treat obesity. In Nutrition and Health, pp. 48-54 [ $\mathrm{T}$ Carr and K Descheemaeker, editors]. Oxford: Blackwell Science.

Jeffrey RW, Wing RR, Thorson C \& Burton LR (1998) Are smaller weight losses or more achievable weight loss goals better in the long term for obese patients. Journal of Consulting and Clinical Psychology 66, 641-645.

McAuley KA, Williams SM, Mann JI, Goulding, A, Chisholm A, Wilson N, Story G, McLay RT, Harper MJ \& Jones IE (2002) Intensive lifestyle changes are necessary to improve insulin sensitivity. Diabetes Care 25, 445-452.

National Audit Office (2001) Tackling Obesity in England, pp. 1-66. London: National Audit Office.
Prentice AM, Goldberg GR, Jebb SA, Black AE, Murgatroyd PR \& Diaz EO (1991) Physiological response to slimming. Proceedings of the Nutrition Society 50, 441-458.

Prentice AM \& Jebb SA (1995) Obesity in Britain: Gluttony or sloth? British Medical Journal 311, 437-439.

Prentice AM \& Jebb SA (2001) Beyond body mass index. Obesity Reviews 2, 141-147.

Prentice AM \& Poppitt SD (1996) Importance of energy density and macronutrients in the regulation of energy intake. International Journal of Obesity 20, Suppl. 2, S18-S23.

Prochaska K \& Diclemente CC (1986) Toward a comprehensive model of change. In Treating Addictive Behaviours: Processes of Change, pp. 3-27 [WR Miller and N Heather, editor]. New York: Plenum.

Scottish Intercollegiate Guidelines Network (1996) Obesity in Scotland. Integrating Prevention with Weight Management. Edinburgh: Royal College of Physicians, Edinburgh.

Williams CL, Gulli MT \& Deckelbaum RJ (2001) Prevention and treatment of childhood obesity. Atherosclerosis Reports 3, 486-497. 